\title{
Radioactivation of Coolant in the E-823 DØ Silicon Tracker
}

\author{
W. S. Freeman
}

$11 / 21 / 00$

\section{Introduction}

The DØ Silicon Microstrip Tracker (SMT) for E-823 surrounds the beam pipe at the interaction region of the $\mathrm{D} \varnothing$ straight section. The central part of the detector consists of six barrel/disk modules with an additional three "F-disks" on each end. There also are two additional, larger disks outside each end of the central detector, called the "H-disks". Each barrel contains four concentric layers of silicon ladders at radial distances ranging from 2.7 to $9.4 \mathrm{~cm}$ from the beam centerline, while the associated F-disks (H-disks) are constructed of wedge-shaped silicon pieces and span the range from 2.6 to $10.5 \mathrm{~cm}(9.5$ to $26 \mathrm{~cm})$. See figure 1 below.

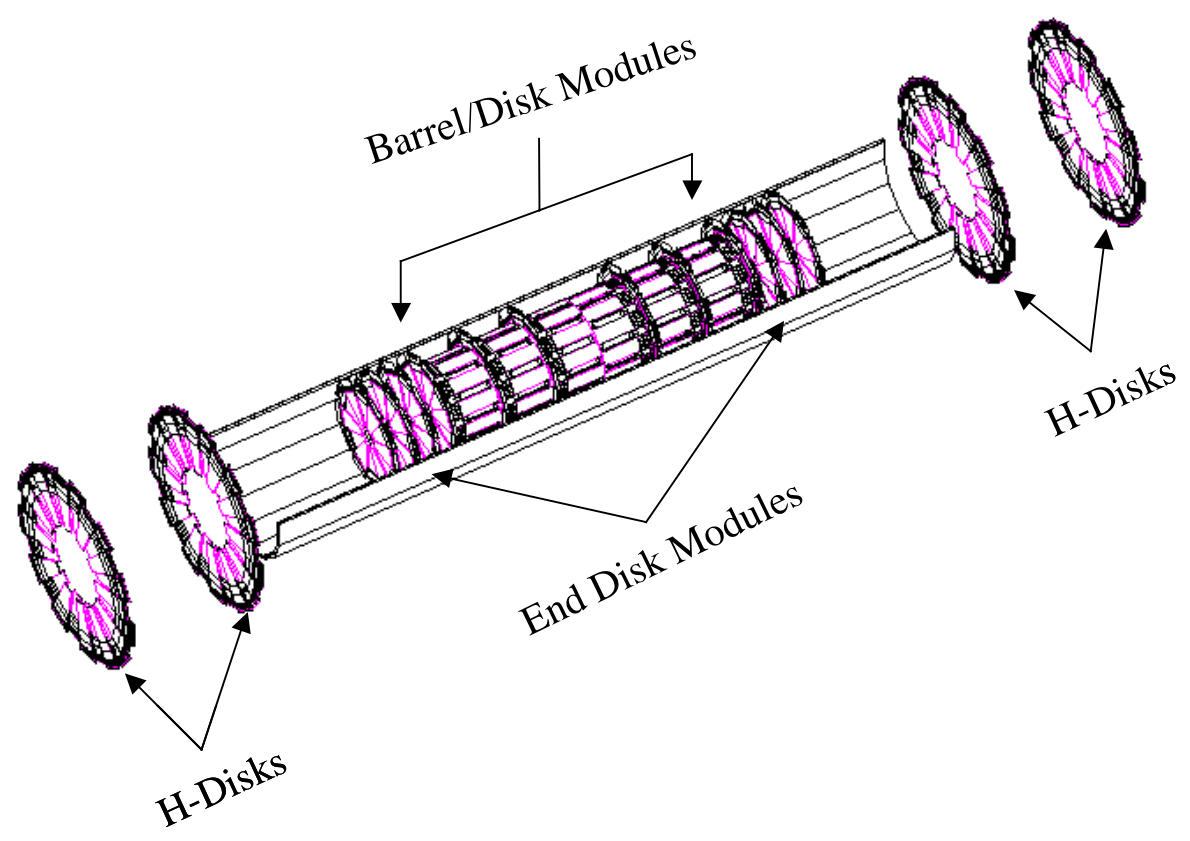

Figure 1 - Overview of DØ Silicon Microstrip tracker

Detector elements, including the silicon and some of the associated electronic readout components, are in contact with and supported by beryllium structures that contain cooling loops through which a coolant mixture of $28 \%$ (by volume) ethylene glycol and water flows to remove excess heat from the detector. Figure 2 illustrates the cooling channel loops for a beryllium bulkhead. Because of its close proximity to the interaction point, the coolant will be subject to a 
high flux of hadrons. The purpose of this note is to estimate the concentration of radioactivity that will be produced in the coolant so that proper consideration can be given to its handling and disposal.

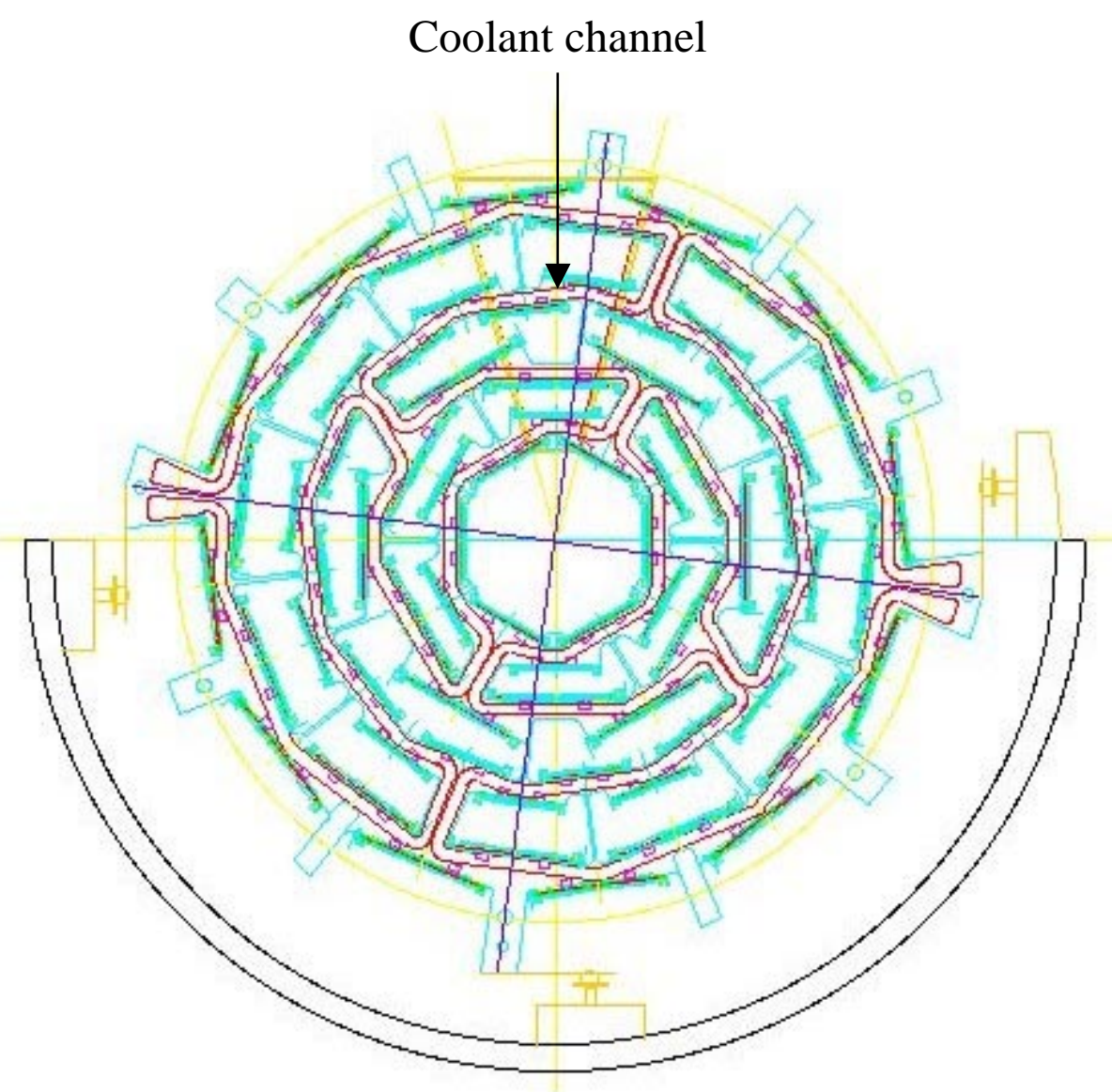

Figure 2 - A Be cooling bulkhead (end view) for a single barrel/disk module, showing the pathway for the ethylene glycol coolant

\section{Methodology}

This note follows the methodology of Fermilab TM-2112 (Revised) by Cossairt ${ }^{1}$. The buildup of specific activity, $a_{i}$, of a radionuclide of type $i$ as a function of the irradiation time, $t_{\text {irrad }}$, in a mixture of chemical elements is given by:

$$
\left.a_{i}\left(t_{\text {irrad }}\right)=\sum_{j} n_{j} \sigma_{j i} \phi\left(1-e^{-\lambda_{i} t_{\text {irad }}}\right) \quad(\mathrm{Bq} \mathrm{cm})^{-3}\right)
$$

\footnotetext{
${ }^{1}$ Fermilab TM-2112, "Calculation of the Radioactivity Produced in the Cooling Loops of the CDF SVX II Detector", J. D. Cossairt (revised, November, 2000)
} 
where $n_{j}$ is the number density $\left(\mathrm{cm}^{-3}\right)$ of the $j t h$ element in the mixture, $\sigma_{j i}$ is the cross section $\left(\mathrm{cm}^{2}\right)$ for producing radionuclide type $i$ by bombarding an atom of element $j, \phi$ is the (constant) hadron flux density $\left(\mathrm{cm}^{-2} \mathrm{sec}^{-1}\right)$, and $\lambda_{i}$ is the decay constant $\left(\mathrm{sec}^{-1}\right)$ for radionuclide $i$. Allowing for decay over a time $t_{\text {decay }}$ following the end of an irradiation cycle yields a specific activity $a_{i}\left(t_{\text {decay }}\right)$ of

$$
a_{i}\left(t_{\text {decay }}\right)=a_{i}\left(t_{\text {irrad }}\right) e^{-\lambda_{i} t_{\text {decay }}} \quad\left(\mathrm{Bq} \mathrm{cm}^{-3}\right)
$$

For the purposes of this note, the detector cooling system was assumed to be divided into six separate irradiation regions, each subject to its own activating flux that depended on location. The specific activity in each region was determined using equations (1) and (2) together with the parameters in the following tables. The total activity in each region was determined by multiplying these specific activities by each region's volume. Summing the total activities over all the regions and dividing by the total volume of the coolant system including its reservoir (200 gallons) yields the concentration of radioactivity in the coolant, assuming uniform mixing.

\section{Parameters}

Ethylene glycol has the chemical formula $\mathrm{C}_{2} \mathrm{H}_{6} \mathrm{O}_{2}$. A $28 \%$ glycol mixture in water $\left(\mathrm{H}_{2} \mathrm{O}\right)$ has the atomic number densities shown in table 1.

\section{Table 1 - Atomic number densities of elements in cooling mixture}

\begin{tabular}{|c|c|}
\hline Element & $n_{j}($ atoms cm \\
& -3 \\
\hline \hline $\mathrm{H}$ & $7.16 \times 10^{22}$ \\
$\mathrm{C}$ & $1.87 \times 10^{22}$ \\
$\mathrm{O}$ & $2.65 \times 10^{22}$ \\
\hline
\end{tabular}

The radionuclides of relevance are shown in Table 2 along with their decay constants and production cross sections for carbon and oxygen target nuclei. Practically speaking, only two radionuclides $\left(\mathrm{H}^{3}\right.$ and $\left.\mathrm{Be}^{7}\right)$ have sufficiently long lifetimes to be potentially relevant to the question of waste disposal. The other isotopes $\left(\mathrm{C}^{11}, \mathrm{~N}^{13}\right.$, and $\left.\mathrm{O}^{15}\right)$ are potentially relevant only from the point of view of spills or leaks in which little or no time is allowed for them to decay. Production cross sections were taken from Barbier ${ }^{2}$, with the exception of that for tritium which

\footnotetext{
${ }^{2}$ M. Barbier, Induced Radioactivity, (North Holland Publishing Co., Amsterdam and London, Wiley Interscience Division, John Wiley and Sons, Inc, New York, 1969).
} 
was taken from Konobeyev and Korovin ${ }^{3}$. Production of tritium via sequential thermal neutron capture on $\mathrm{H}^{1}$ was ignored due the small cross sections and presumed low thermal neutron flux in the detector region. Production of $\mathrm{Be}^{7}$ from $\mathrm{Be}^{9}$ in the bulkheads was also ignored, due to the very small number density of Be atoms $\left(\sim 7.5 \times 10^{17}\right.$ atoms $\mathrm{cm}^{-3}$ per year $)$ that is expected to appear in the coolant, assuming an annual reduction in thickness of the cooling channel walls of $2.5 \times 10^{-3} \mathrm{~cm}$ and a production cross section that is comparable to the production cross section for the other targets $(\sim 10-35 \mathrm{mb})$.

Table 2 - Decay constants and production cross-sections

\begin{tabular}{|c|c|c|c|}
\hline Radionuclide, $\boldsymbol{i}$ & $\begin{array}{c}\text { Decay Constants, }{ }^{\bullet} \boldsymbol{i} \\
\left(\mathrm{sec}^{-1}\right)\end{array}$ & \multicolumn{2}{|c|}{$\begin{array}{c}\text { Cross Sections, } \boldsymbol{\bullet}_{\boldsymbol{j} i} \\
(\mathrm{mb})\end{array}$} \\
\cline { 3 - 4 } & & $\mathrm{j}=$ =Carbon & $\mathrm{j}=$ Oxygen \\
\hline \hline $\mathrm{H} 3$ & $1.78 \times 10^{-9}$ & 20 & 25 \\
$\mathrm{Be} 7$ & $1.51 \times 10^{-7}$ & 10 & 8 \\
$\mathrm{C} 11$ & $5.59 \times 10^{-4}$ & 25 & 10 \\
$\mathrm{~N} 13$ & $1.16 \times 10^{-3}$ & -- & 5 \\
$\mathrm{O} 15$ & $5.67 \times 10^{-3}$ & -- & 35 \\
\hline
\end{tabular}

The fluence delivered to each region was derived from the integrated radiation dose calculated at the central radius of the region, assuming a dose-to-fluence conversion factor of $2.8 \times 10^{13}$ hadrons $/ \mathrm{cm}^{2}$ per Mrad, appropriate for $500 \mathrm{MeV}$ protons ${ }^{4}$. The parameters assumed for each coolant region are shown in Table $3^{5}$.

Table 3 - Coolant region parameters

\begin{tabular}{|c|c|c|c|c|c|}
\hline Region & $\begin{array}{c}\text { Radius } \\
(\mathrm{cm}) \\
\end{array}$ & $\begin{array}{c}\text { Volume } \\
\left(\mathrm{cm}^{3}\right) \\
\end{array}$ & $\begin{array}{c}\text { Dose } \\
\left(\mathrm{MRads}_{\mathrm{f}} \mathrm{fb}^{-1}\right) \\
\end{array}$ & $\begin{array}{c}\text { Fluence }\left(\times 10^{-12}\right) \\
\left(\text { part. } / \mathrm{cm}^{2} / \mathrm{fb}^{-1}\right) \\
\end{array}$ & Description \\
\hline 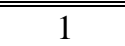 & $3.0-4.3$ & 29.8 & 0.24 & 6.72 & Barrel Layer 1 \\
\hline 2 & $4.3-5.9$ & 46.8 & 0.14 & 3.92 & Barrel Layer 2 \\
\hline 3 & $5.9-8.2$ & 66.7 & 0.080 & 2.24 & Barrel Layer 3 \\
\hline 4 & $8.2-11.4$ & 155.3 & 0.046 & 1.29 & Barrel Layer 4 + F-disks \\
\hline 5 & $11.4-18.0$ & 1057.7 & 0.024 & 0.67 & $\begin{array}{l}\text { Hose connections to barrel and } \\
\text { F-disks }+ \text { central manifolds }\end{array}$ \\
\hline 6 & $18.0-26.9$ & 732.8 & 0.012 & 0.34 & $\begin{array}{l}\text { H-disks, hose connections, end } \\
\text { manifolds, end connections }\end{array}$ \\
\hline
\end{tabular}

The assumed irradiation cycle is shown in Table 4. To facilitate comparison, this is the same cycle that was assumed in TM-2112. Note that a total of $3 \mathrm{fb}^{-1}$ is assumed to be delivered in the

\footnotetext{
${ }^{3}$ A. Yu. Konobeyev and Yu. A. Korovin, "Tritium Production in Materials from C to Bi Irradiated with Nucleons of Intermediate and High Energies", Nucl. Instr. And Meth. In Phys. Res. B82 (1993) 103-115.

${ }^{4}$ Same as TM-2112 (Revised)
} 
first two years of running, followed by a one year shutdown followed by an additional $5 \mathrm{fb}^{-1}$ delivered over the next two years. The actual cycle that is eventually realized will depend on the details of accelerator and detector performance, but integrated luminosities of 2 to $3 \mathrm{fb}^{-1}$ over the first two years are consistent with current plans.

Table 4 - Integrated luminosity profile

\begin{tabular}{|c|c|c|c|}
\hline Year & $\begin{array}{c}\text { Integrated } \\
\text { luminosity } \\
\text { (fb }^{-1} \text { per yr) }\end{array}$ & $\begin{array}{c}t_{\text {irrad }} \\
(\mathrm{yr})\end{array}$ & $\begin{array}{c}t_{\text {decay }} \\
(\mathrm{yr})\end{array}$ \\
\hline \hline 1 & 1 & 0.8 & 0.2 \\
2 & 2 & 0.8 & 0.2 \\
3 & 0 & 0.0 & 1.0 \\
4 & 2 & 0.8 & 0.2 \\
5 & 3 & 0.8 & 0.2 \\
\hline
\end{tabular}

\section{Results}

Concentrations were calculated immediately following the end of an irradiation cycle as well as 0.2 years after beam turn-off for each year. For year 2 and greater, the residual contributions from prior years, corrected for continued decay were included. The calculation assumes that there is no exchange of the coolant over the entire 5-year irradiation cycle. Intermediate replacement of the coolant would result in lower concentrations than those calculated here.

Table 5 shows the results.

Table 5 - Calculated radionuclide concentrations in $\mathrm{pCi} \mathrm{cm}^{-3}$. The numbers in the first row for each year are the concentrations immediately after the end of running in that year $\left(t_{\text {irrad }}=0.8\right.$ yrs). The numbers in the second row for each year are the concentrations 0.2 yrs later $\left(t_{\text {decay }}=0.2\right.$ yrs). Note that there is no integrated luminosity in year 3 .

\begin{tabular}{|c|c|c|c|c|c|}
\hline Year & $\mathbf{H}^{\mathbf{3}}$ & $\mathbf{B e}^{\mathbf{7}}$ & $\mathbf{C}^{\mathbf{1 1}}$ & $\mathbf{N}^{\mathbf{1 3}}$ & $\mathbf{O}^{\mathbf{1 5}}$ \\
\hline 1 & 0.108 & 0.925 & 1.737 & 0.314 & 2.199 \\
& 0.107 & 0.357 & 0.000 & 0.000 & 0.000 \\
\hline 2 & 0.318 & 1.858 & 3.474 & 0.628 & 4.399 \\
& 0.314 & 0.717 & 0.000 & 0.000 & 0.000 \\
\hline 3 & 0.301 & 0.016 & 0.000 & 0.000 & 0.000 \\
& 0.297 & 0.006 & 0.000 & 0.000 & 0.000 \\
\hline 4 & 0.500 & 1.850 & 3.474 & 0.628 & 4.399 \\
& 0.495 & 0.714 & 0.000 & 0.000 & 0.000 \\
\hline 5 & 0.797 & 2.791 & 5.211 & 0.943 & 6.598 \\
& 0.788 & 1.076 & 0.000 & 0.000 & 0.000 \\
\hline
\end{tabular}

\footnotetext{
${ }^{5}$ Bill Cooper, private communication, October 19, 2000.
} 


\section{Conclusions}

The calculated radionuclide concentrations for all the isotopes listed in Table 5 are quite small. They do not represent a personnel hazard or approach a regulatory limit. For example, the regulatory limit for $\mathrm{H}^{3}$ in drinking water is $20 \mathrm{pCi}$ per $\mathrm{ml}$, which is 25 times greater than the calculated concentration after year 5 . The corresponding drinking water limit for $\mathrm{Be}^{7}$ is $40 \mathrm{pCi}$ per $\mathrm{ml}$, which is approximately 14 times the calculated concentration for that isotope. While the calculated radionuclide concentrations are negligible from a regulatory perspective, ethylene glycol still must be disposed of as Illinois Special Waste. Because it will have been subject to irradiation, it will still be necessary to verify the low levels of radioactivity in the coolant via sampling at the time of disposal. 